\title{
Hipotiroidismo congénito. Aspectos clínicos y ultrasonográficos
}

\author{
KARLA MOËNNE B. ${ }^{1}$, XIMENA ORTEGA F. ${ }^{1}$, MANUELA PÉREZ M. ${ }^{2}$, \\ VERÓNICA MERICQ G. ${ }^{3}$, \\ 1. Radióloga Infantil, Clínica Las Condes. \\ 2. Becada Radiología Pediátrica, Universidad de Chile, Clínica Las Condes. \\ 3. Endocrinóloga Infantil, Clínica Las Condes, Universidad de Chile.
}

\begin{abstract}
Clinical and ultrasound features of congenital hypothyroidism

Congenital hypothyroidism is a condition where a newborn has decreased or absent thyroid function and thyroid hormone production. It is the most common cause of preventable mental retardation and its early diagnosis can only be achieved through systematic neonatal screening because its clinical manifestations are usually late. The etiologic study of this condition relies heavily on nuclear medicine and ultrasound, describing various findings. This research analyzed the characteristics of the ultrasound patterns observed in these children and their correlation with the most common etiologies. The use of ultrasound allows selecting children that require scintigraphic studies, decreasing the use of radiation in neonates.

(Key words: Congenital hypothyroidism, ultrasound, thyroid scintigraphy).

Rev Chil Pediatr 2014; 85 (1): 98-105
\end{abstract}

\section{RESUMEN}

El hipotiroidismo congénito se define como la condición de déficit de la producción de hormonas tiroideas, que se encuentra presente desde el nacimiento. Corresponde a la causa más común de retardo mental prevenible y su diagnóstico precoz sólo se logra a través de la pesquisa sistemática neonatal, debido a que las manifestaciones clínicas son habitualmente tardías. El estudio etiológico específico se apoya fundamentalmente en la medicina nuclear y el ultrasonido, describiéndose hallazgos variados. Revisamos las características de los patrones ultrasonográficos observados en estos niños y su correlación con las etiologías más frecuentes. El uso de ultrasonografía permite seleccionar los niños que requieren estudio cintigráfico, disminuyendo el uso de radiación en neonatos.

(Palabras clave: Hipotiroidismo congénito, ultrasonido, cintigrafía tiroidea).

Rev Chil Pediatr 2014; 85 (1): 98-105

Recibido el 18 de enero de 2013, devuelto para corregir el 10 de agosto de 2013, segunda versión 14 de octubre de 2013 , aceptado para publicación el 30 de diciembre de 2013.

Este trabajo cumple con los requisitos sobre consentimiento /asentimiento informado, comité de ética, financiamiento, estudios animales y sobre la ausencia de conflictos de intereses según corresponda.

Correspondencia a:

Ximena Ortega F.

E-mail: xortega@clinicalascondes.cl 


\section{Introducción}

El hipotiroidismo congénito (HC) se define como la condición de déficit en la producción de hormonas tiroideas que se encuentra presente desde el nacimiento ${ }^{1}$. Debido al esencial rol que juegan las hormonas tiroideas en la embriogénesis, crecimiento y desarrollo del sistema nervioso, su déficit origina retardo mental $(\mathrm{RM})^{2}$, siendo la principal causa de discapacidad intelectual prevenible ${ }^{3}$.

El HC puede ser: primario cuando la falla se encuentra a nivel de la glándula tiroides, secundario cuando existe un déficit de hormona tiroestimulante (TSH) o terciario, cuando el defecto está en la producción de hormona liberadora de $\mathrm{TSH}^{4}$.

El HC primario puede obedecer a múltiples etiologías, entre las cuales destacan las alteraciones primarias del desarrollo de la glándula (disgenesia o disembriogénesis) y de la biosíntesis hormonal, (dishormogénesis), que representan el $85 \%$ y $15 \%$ respectivamente de las causas en países sin déficit de ingesta de yodo $^{1,3}$.

La disembriogénesis comprende una serie de alteraciones del desarrollo, que van desde la ausencia total de la glándula tiroides ("atireosis"), a la presencia de remanentes de la glándula que pueden estar localizados en la región anatómica normal (hipoplasia) o en algún lugar de la zona de descenso habitual a través del conducto tirogloso (ectopia), correspondiendo esta última a $2 / 3$ de los casos de disgenesia tiroidea $^{5}$. Si bien la relación entre migración anómala y disfunción no es clara, existiendo individuos que tienen una secreción residual y suelen debutar en forma más tardía con su hipotiroidismo ${ }^{6}$, la recomendación actual es tratar indistintamente a estos pacientes para prevenir complicaciones secundarias a hipertrofia del tejido ectópico lingual o sublingual ${ }^{6}$. El remanente del trayecto embrionario puede persistir como un lóbulo piramidal, conducto tirogloso persistente o quiste tirogloso, en algunos de los cuales también se ha identificado tejido tiroideo remanente ${ }^{6}$.

Desde el punto de vista funcional, la dishormonogénesis abarca una amplia gama de trastornos, que incluyen defectos hereditarios que corresponden a mutaciones en los genes que codifican las proteínas responsables de prácticamente todos los pasos de la biosíntesis y secreción de la hormona tiroidea ${ }^{2}$. Se ha descrito un patrón hereditario autosómico recesivo en la dishormonogénesis ${ }^{7}$.

Desde el punto de vista clínico, el $\mathrm{HC}$ se clasifica en permanente y transitorio, según la necesidad de suplementación de hormona tiroidea; el primer grupo requiere tratamiento de por vida y el segundo normaliza la producción hormonal en los primeros meses o años de vida, pudiendo prescindir posteriormente del aporte exógeno de la hormona ${ }^{4}$. En esta categoría se mencionan además los llamados "hipotiroidismos subclínicos", que corresponden a un grupo de entidades entre las que se encuentran recién nacidos o lactantes que presentan alza aislada de TSH con hormonas tiroideas normales, que generalmente se resuelven los primeros meses o años. El bajo peso de nacimiento y los trastornos tiroideos maternos son algunos de los factores de riesgo que se asocian a estos cuadros. En la actualidad existe consenso de tratar sin retardo prácticamente la totalidad de los $\operatorname{casos}^{1,2}$.

La prematuridad también se vincula a un cierto grado de disfunción tiroidea transitoria similar, pero que no se considera como $\mathrm{HC}^{10}$.

\section{Diagnóstico}

El diagnóstico clínico de $\mathrm{HC}$ en neonatos resulta complejo por lo que se recomienda efectuar tamizaje, determinando niveles hormonales en sangre. Las imágenes cumplen un importante rol en la determinación del diagnóstico etiológico del HC.

Diagnóstico clínico: Las manifestaciones clínicas iniciales del HC son casi inexistentes o muy sutiles, por lo que la mayor parte de los niños que no han sido diagnosticados mediante tamizaje neonatal serán pesquisados clínicamente después de 2 a 3 meses de vida, lo que involucra riesgo de daño neurológico permanente ${ }^{2}$. Esta aparición tardía de síntomas clínicos se interpreta como secundaria al rol protector del paso transplacentario de hormonas tiroideas maternas al feto $(25$ a $50 \%$ del 
valor plasmático normal medido en sangre de cordón $)^{4}$.

En el período neonatal se deben considerar los siguientes antecedentes, síntomas y signos para sospechar clínicamente el diagnóstico de $\mathrm{HC}$ :

- Antecedentes: edad gestacional superior a 41 semanas $(20 \%)$, peso de nacimiento sobre el percentil 90 (30\%).

- Síntomas y signos: letargia, hipotermia, hipoactividad, llanto ronco, dificultad en la alimentación, macroglosia, presencia de fontanela posterior amplia ( $>$ a $5 \mathrm{~mm}$ ), hernia umbilical, piel áspera y seca ${ }^{2,4}$.

\section{Tamizaje}

Dada la dificultad para efectuar en forma precoz el diagnóstico de $\mathrm{HC}$ en base a parámetros clínicos, es necesario realizar una búsqueda activa mediante tamizaje universal. Esta estrategia se aplica en diversos países desde los años $70^{1}$, por recomendación de la Organización Mundial de la Salud. En Chile, el Programa Nacional de Búsqueda Masiva de Fenilcetonuria e $\mathrm{HC}$ fue desarrollado en forma piloto a partir del año 1992 por el Ministerio de Salud, instaurándose la determinación obligatoria de TSH y fenilalanina en muestra de sangre de talón en tarjeta de papel filtro, obtenida entre las 48 y 72 h de vida en los recién nacidos de término y entre $5^{\circ}-7^{\circ}$ día de vida en los de pretérmino ${ }^{5}$. Este programa ha contribuido a mejorar la calidad de vida de los niños chilenos al prevenir la discapacidad que la enfermedad produce si no es detectada y tratada desde el período neonatal ${ }^{5}$.

El valor de corte para la TSH en el Programa Nacional de Chile es de $15 \mathrm{mUI} / \mathrm{ml}$ por lo que resultados superiores requieren confirmación plasmática inmediata, determinando T4 y TSH en sangre. Una vez obtenida la muestra, independiente del algoritmo de trabajo que variará según el centro y paciente, es necesario tener presente no retrasar jamás el inicio del tratamiento que debe comenzar antes de los 15 días de vida, aportando levotiroxina ${ }^{6,9}$.

Antes de la instalación de los métodos de tamizaje, la incidencia de $\mathrm{HC}$ se calculaba en el rango de 1:7.000 - 1:10.000. La aplicación regional de las políticas de prevención secun- daria aumentó esta tasa a 1:3.500- 1:4.000, transformándolo en la endocrinopatía más frecuente del recién nacido $(\mathrm{RN})^{3}$.

\section{Diagnóstico por imágenes}

El estudio por imágenes utilizado convencionalmente ha sido el cintigrama o cintigrafía tiroidea y en las últimas décadas se ha incorporado la ultrasonografía (US) tiroidea. Ambas técnicas juegan un rol preponderante para precisar el diagnóstico etiológico del $\mathrm{HC}$ y determinar tanto la anatomía como la localización del tejido tiroideo. Los hallazgos pueden ser relevantes tanto desde el punto de vista pronóstico como para conocer si existe patrón hereditario en la enfermedad ${ }^{7}$. Los exámenes de imágenes se utilizan en conjunto con la determinación de anticuerpos antitiroideos y tiroglobulina, siendo esta última un excelente marcador de presencia de tejido tiroideo.

Una vez realizado el diagnóstico de $\mathrm{HC}$, la norma chilena indica la realización inmediata de un cintigrama tiroideo ${ }^{5}$. En la literatura existen publicaciones que sugieren efectuar inicialmente US y, dependiendo de su resultado, utilizar selectivamente el cintigrama ${ }^{8,10}$.

El cintigrama tiroideo permite una evaluación funcional de la glándula tiroides mediante medicina nuclear, utilizando $\mathrm{I}^{123} \mathrm{o} \mathrm{Tc}^{99 \mathrm{~m}}$, siendo este último el radiofármaco de elección ${ }^{6}$. Se ha empleado clásicamente para detectar agenesia o ectopia tiroidea ${ }^{7}$, a pesar que la ausencia de captación no descarta la presencia de tejido tiroideo $^{9,11}$. El eventual efecto oncogénico de la radiación empleada en los neonatos, si bien la dosis utilizada es muy baja ${ }^{7}$, y por otra parte el carácter no invasivo y ausencia de efectos secundarios de la US sumados al gran desarrollo de esta técnica en los últimos años con transductores de alta resolución y uso de tecnología Doppler color, han posicionado a la US en un rol muy relevante por la importante información que aporta respecto del tamaño y características morfológicas de la glándula ${ }^{7}$.

Existe consenso en la literatura que el uso combinado de ambas técnicas de imágenes mejora la capacidad de efectuar un correcto diagnóstico etiológico ${ }^{9}$, por lo que actualmente se consideran técnicas complementarias. Históricamente las publicaciones han mostrado 
mayor sensibilidad de la cintigrafía en la pesquisa de tejido ectópico, lo que ha constituido la principal limitación de la US; publicaciones más recientes han reportado mejoría en la sensibilidad de la US para la pesquisa de tejido ectópico con operadores entrenados, uso complementario de Doppler color y utilización de transductores de mayor frecuencia ${ }^{12-14}$. En un estudio comparativo efectuado en 1988, Muir y cols reportaron $0 \%$ de sensibilidad para la US en la detección de tejido ectópico, utilizando transductores de 5-7 $\mathrm{MHz}^{13}$. Siete años más tarde, Takashima y cols, empleando transductores de 7,5-10 $\mathrm{MHz}$ obtuvieron cifras de sensibilidad cercanas al $75 \%$ para el US $^{8}$ y 3 años después, Ueda y cols alcanzaron 100\% de sensibilidad empleando equipos similares ${ }^{14}$.

Los hallazgos ultrasonográficos en el HC son variados y si bien pueden superponerse en las distintas causas, se han identificado cuatro patrones morfológicos que se relacionan más específicamente con determinadas etiologías ${ }^{15}$.

\section{Tabla 1. Clasificación de los patrones ecográficos} en el hipotirodismo congénito

\begin{tabular}{|l|}
\hline 1. Tiroides normal \\
\hline 2. Tiroides aumentada de tamaño \\
\hline 3. Tiroides disminuida de tamaño \\
4. Tiroides ausente \\
- Ausencia total \\
- Tiroides ectópico \\
\hline
\end{tabular}

A continuación describiremos las características de estos cuatro tipos morfológicos, con énfasis en las asociaciones clínicas (tabla 1).

\section{Tiroides normal}

Se define como una glándula en posición normal, de tamaño dentro de límites normales para la edad (tabla 2) ${ }^{16}$, cuyo parénquima es discretamente más ecogénico que la musculatura adyacente y evidencia estructura ecográfica homogénea (figura 1), sin lesiones focales intraparenquimatosas ni alteración del flujo vascular en el estudio Doppler color. Se incluyen en este grupo los casos de asimetría tiroidea $^{17}$, en los cuales un lóbulo es de discreto mayor tamaño y corresponde sólo a una variante anatómica sin significado patológico.

El tipo de HC más frecuentemente asociado a este patrón corresponde al $\mathrm{HC}$ transitorio ${ }^{18}$. Como se señaló anteriormente, se describen casos en los que el cintigrama no evidencia tejido tiroideo y la US resulta normal, lo que estaría relacionado principalmente con supresión de TSH por tratamiento, transferencia de anticuerpos maternos o degeneración quística ${ }^{11,15}$.

\section{Tiroides aumentada de tamaño}

En estos casos, el hallazgo central es un aumento de tamaño de la glándula (diámetros longitudinal, transversal o anteroposterior $>+2$ DS respecto a los valores de referencia normales para la edad en tabla 2$)^{8,16}$, frecuentemente asociado a aumento del flujo vascular

Tabla 2. Medida de la glándula tiroides en 100 recién nacidos sanos dentro de la primera semana de vida (modificada desde referencia 15)

\begin{tabular}{|c|c|c|c|c|c|c|c|}
\hline & & \multicolumn{2}{|c|}{ Niños $(n=49)$} & \multicolumn{2}{|c|}{ Niñas $(n=51)$} & \multicolumn{2}{|c|}{ Todos } \\
\hline & & Media (DS) & Rango & Media (DS) & Rango & Media (DS) & Rango \\
\hline \multirow[t]{2}{*}{ Largo $(\mathrm{cm})$} & $\mathrm{D}$ & $1,99(0,22)$ & $1,6-2,5$ & $1,88(0,26)$ & $0,9-2,5$ & $1,94(0,24)$ & $0,9-2,5$ \\
\hline & 1 & $1,96(0,21)$ & $1,6-2,4$ & $1,92(0,27)$ & $0,9-2,4$ & $1,94(0,24)$ & $0,9-2,4$ \\
\hline \multirow[t]{2}{*}{ Ancho $(\mathrm{cm})$} & $D$ & $0,87(0,17)$ & $0,5-1,4$ & $0,86(0,13)$ & $0,6-1,2$ & $0,87(0,15)$ & $0,5-1,4$ \\
\hline & 1 & $0,89(0,14)$ & $0,6-1,3$ & $0,88(0,17)$ & $0,6-1,4$ & $0,89(0,16)$ & $0,6-1,4$ \\
\hline \multirow[t]{2}{*}{ Diámetro AP (cm) } & $\mathrm{D}$ & $0,96(0,12)$ & $0,7-1,3$ & $0,97(0,20)$ & $0,6-2,0$ & $0,97(0,16)$ & $0,6-2,0$ \\
\hline & 1 & $0,91(0,13)$ & $0,7-1,2$ & $0,99(0,20)$ & $0,7-1,9$ & $0,95(0,17)$ & $0,7-1,9$ \\
\hline \multirow[t]{2}{*}{ Volumen (ml) } & $\mathrm{D}$ & $0,84(0,24)$ & $0,3-1,4$ & $0,78(0,22)$ & $0,5-1,7$ & $0,81(0,23)$ & $0,3-1,7$ \\
\hline & 1 & $0,79(0,19)$ & $0,4-1,3$ & $0,84(0,29)$ & $0,4-1,7$ & $0,82(0,24)$ & $0,4-1,7$ \\
\hline Volumen total (ml) & & $1,63(0,37)$ & $0,7-2,4$ & $1,61(0,44)$ & $1,0-3,3$ & $1,62(0,41)$ & $0,7-3,3$ \\
\hline
\end{tabular}

El largo, ancho, diámetro AP y volumen se dan para cada lóbulo junto con el volumen combinado de los dos lóbulos $(D=$ lóbulo derecho; I = lóbulo izquierdo). 


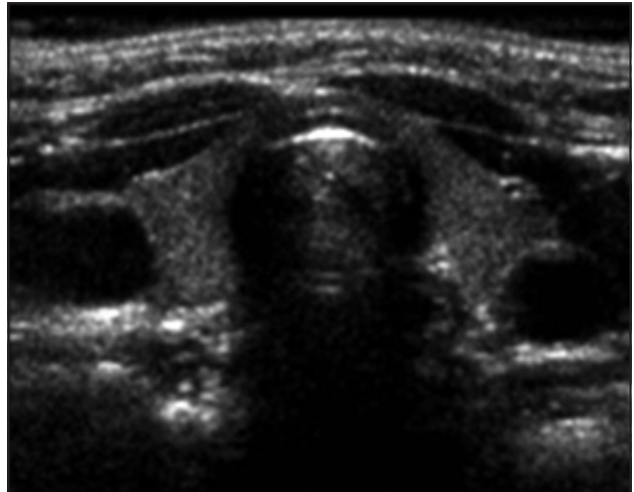

Figura 1. Corte transversal de US tiroidea a nivel del istmo, que evidencia glándula de aspecto normal.

y a veces con estructura ultrasonográfica algo heterogénea (figura 2$)^{8}$. La cintigrafía puede evidenciar una glándula aumentada de tamaño con aumento de la captación del isótopo ${ }^{19}$ pero frecuentemente subestima el volumen tiroideo debido a su resolución bidimensional ${ }^{8}$.

Este patrón se asocia fuertemente a los casos de dishormonogénesis, aunque ha sido descrito también en casos de alza transitoria de $\mathrm{TSH}$, en los cuales el parénquima tiende a ser algo más hipoecogénico ${ }^{16}$.

Puede asociarse al antecedente de uso materno de medicamentos antitiroideos durante el embarazo.

\section{Tiroides disminuida de tamaño}

En esta categoría se incluyen tanto las formas de hipoplasia lobar completa, donde no existe desarrollo de un lóbulo completo de la glándula tiroides (hemiaplasias o hemiagenesias), como las hipoplasias difusas en las que se observa disminución de tamaño de todos los diámetros de una glándula ortotópica y bilobulada (figura 3). En ambos casos, tanto la estructura ultrasonográfica como la ecogenicidad de la glándula tienden a ser normales ${ }^{16}$.

Los casos de hemiaplasia tiroidea son raros, reportándose que corresponden al 0,05$3,7 \%$ del total de casos de $\mathrm{HC}^{17,18}$.

El lóbulo izquierdo se encuentra más frecuentemente ausente ${ }^{16} \mathrm{y}$ en la literatura se ha documentado $\mathrm{HC}$ en 1 de cada 90 niños con esta condición ${ }^{8}$, por lo que tiende a ser considerada de buen pronóstico.

Las hipoplasias difusas corresponden aproximadamente al 5\% de los casos de hipotiroidismo disembriogénico; tienden a ser glándulas tan hipofuncionantes que frecuentemente no son detectadas por la cintigrafía ${ }^{20}$.

\section{Tiroides ectópico/ausente}

En los casos en que no se demuestra tejido normal en el lecho tiroideo es fundamental distinguir agenesia de ectopia, siendo esta última mucho más frecuente. La disrupción de la migración normal de la glándula tiroides puede ocasionar tejido ectópico en cualquier parte del trayecto del conducto tirogloso, por lo que en el examen ultrasonográfico se debe efectuar un cuidadoso barrido transversal cervical a lo largo de toda la línea media ${ }^{12}$.

El diagnóstico ultrasonográfico de tejido tiroideo ectópico depende de la técnica y experiencia del operador; la utilización del

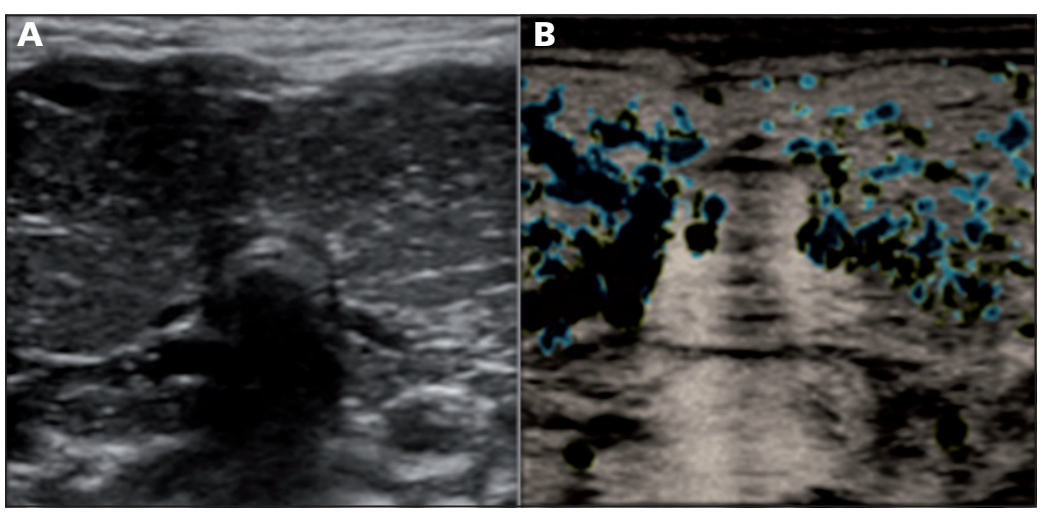

Figura 2. RN 11 días de vida, TSH $228 \mathrm{uIU} / \mathrm{ml}$. La cintigrafía tiroidea mostró aumento de captación difuso del Tc99. Imágenes transversales de US tiroídea a nivel del istmo, evidencian significativo bocio hipoecogénico (A) asociado a marcado aumento del flujo vascular (B). 


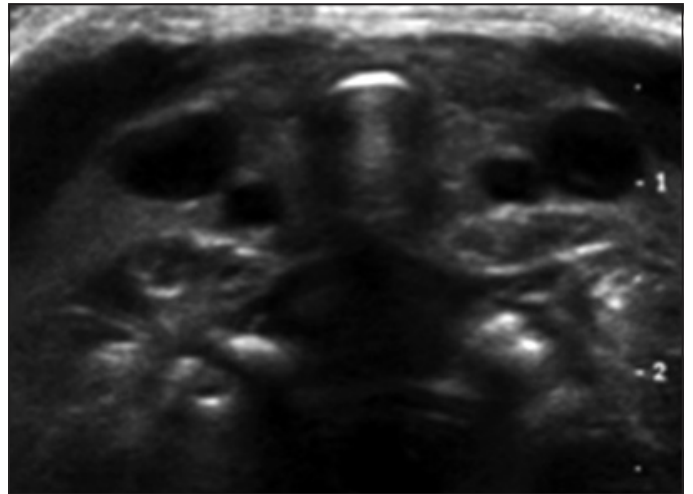

Figura 3. RN 14 días, TSH 984 uIU/ml. Imagen transversal de US tiroídea a nivel del istmo; se reconoce marcada disminución de los diámetros anteroposterior y transversal de la glándula, sin otras alteraciones.

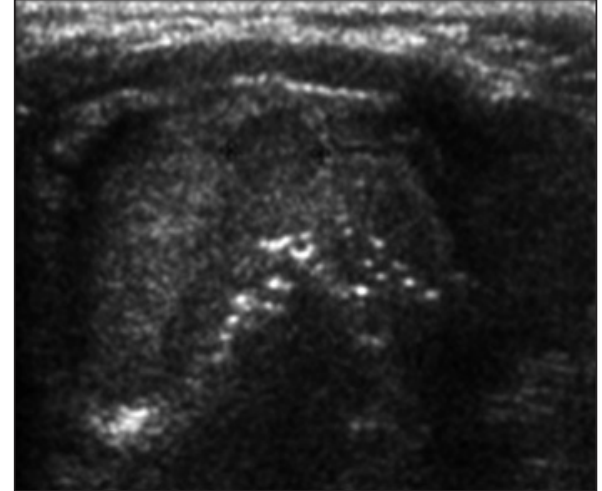

Figura 4. RN 24 días, TSH 838 uIU/ml. Imagen transversal de US tiroídea en la base de la lengua donde muestra nódulo discretamente hipoecogénico respecto del tejido lingual adyacente.
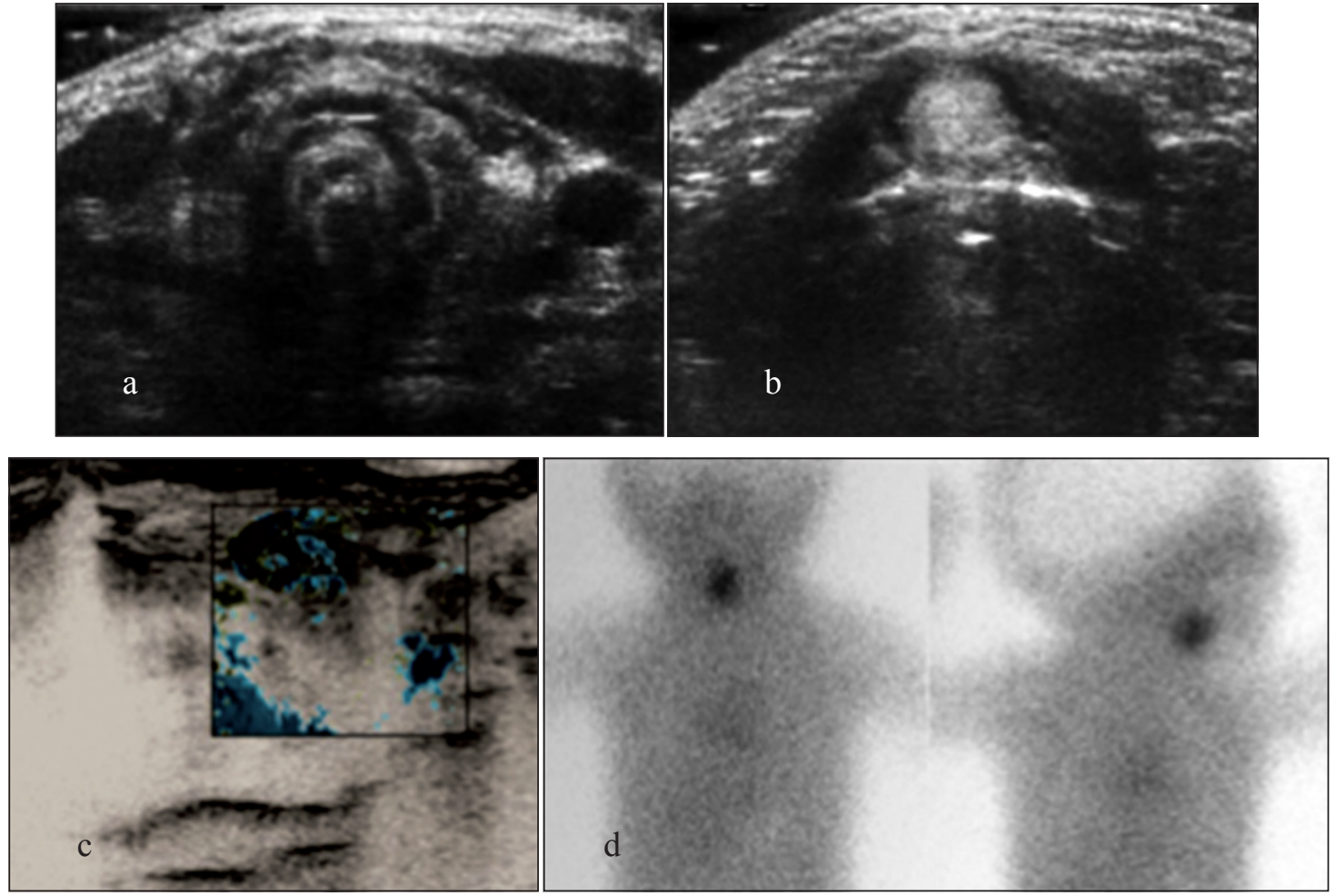

ANTERIOR

LAT DER

Figura 5a. RN 1 mes, TSH 222 uIU/ml. Imagen transversal de US tiroídea a nivel pretraqueal, que muestra lecho tiroideo vacío. 5b. Imagen transversal de US a nivel del hueso hioides evidencia nódulo hiperecogénico situado inmediatamente anterior al hioides. 5c. Imagen longitudinal de US del mismo nódulo, mostrando intenso flujo vascular. 5d. Cintigrafía tiroídea muestra captación ectópica del trazador Tc99 en situación parasagital derecha en la región posterior del piso de la boca a nivel de la línea media, compatible con una tiroides ectópica. (Gentileza Dra. Neubauer). 
Doppler color aumenta la pesquisa del tejido tiroideo ectópico sublingual con este método de estudio ${ }^{21}$. La cintigrafía resulta de utilidad en la pesquisa del tejido tiroideo ectópico, por lo que cumple rol complementario a la US en estos casos.

La ubicación más frecuente del tejido ectópico es la base de la lengua y otra localización habitual es a nivel del hueso hioides. En US, la ecogenicidad del tejido tiroideo ectópico se describe en relación a los tejidos adyacentes, pudiendo aparecer hipoecogénico (figura 4) o hiperecogénico (figura 5) respecto de ellos. En la serie de Takashima y cols, se describieron nódulos ectópicos discretamente hipoecogénicos respecto del tejido lingual y un nódulo hiperecogénico respecto de los vientres anteriores del músculo digástrico adyacente ${ }^{8}$. Existen localizaciones en las que la US presenta mayor dificultad para pesquisar el tejido ectópico, como por ejemplo nódulos localizados en la pared de la hipofaringe, donde la interfaz con el aire genera un intenso artefacto que puede hacer imposible su visualización, por lo que en esos casos la cintigrafía cumple un rol muy importante $^{6}$.

Después de analizar los diversos patrones que se observan en el HC, es importante destacar que las alteraciones morfológicas de la glándula tiroides aportan información relevante que en la mayoría de los pacientes permite establecer la etiología del trastorno.

Si bien los hallazgos ultrasonográficos son variados y pueden superponerse en las diversas causas, existen patrones ecográficos que podrían orientar, como por ejemplo:

- Aumento difuso de tamaño tiroideo con aumento del flujo, en algunas dishormonogénesis.

- Glándulas normales en los casos de Hipertirotropinemia transitoria.

- Hemiaplasia o ectopia, en los casos de hipotiroidismo disembriogénico.

La importancia de lograr un correcto diagnóstico etiológico radica en el valor pronóstico y consejo genético. A modo de ejemplo, la detección de tejido ectópico funcional es importante debido al mejor desempeño intelectual de estos pacientes respecto de las aplasias puras ${ }^{7}$.
Desde el punto de vista de la consejería genética, resulta importante diferenciar los casos de disgenesia, generalmente esporádicos, de las dishormogénesis que tienden a seguir un patrón hereditario autosómico recesivo ${ }^{7,11}$. Como ya se comentó anteriormente, es necesario destacar que el tratamiento del HC depende del defecto bioquímico y no de las imágenes ${ }^{21}$.

\section{Conclusiones}

El US puede ser usado como estudio inicial de imágenes en niños con $\mathrm{HC}$, fundamentalmente para conocer la anatomía de la glándula: tamaño, aspecto, localización, flujo vascular, presencia de tejido ectópico y así orientar a la posible causa del trastorno y ayudar a establecer el diagnóstico evitando el uso de radiación. La cintigrafía debería reservarse para los pacientes que presentan hallazgos ultrasonográficos equívocos.

\section{Referencias}

1.- Grob F, Martínez-Aguayo F: Hipotiroidismo congénito: un diagnóstico que no debemos olvidar. Rev Chil Pediatr 2012; 83 (5): 482-91.

2.- Cattani A: Trastornos tiroideos neonatales. Boletín de la Escuela de Medicina. Vol. 29, Nro 3, Año 2000.

3.- Abodovsky N, Vivanco X, Cuello X, et al: Detección precoz de hipotiroidismo congénito en Chile. Resultados en 24 meses. Rev Chil Pediatr 1995; 66 (3): 140-4.

4.- Rastogi M, LaFranchi S: Congenital hypothyroidism. Orphanet J Rare Dis 2010, 5; 17.

5.- Becerra $C$ : Hipotiroidismo congénito y fenilcetonuria en el niño. Rev Chil Pediatr 2008; 79 Supl (1): 96-102.

6.- Treves ST, Baker A, Fahey FH, et al: Nuclear medicine in the first year of life. J Nucl Med 2011; 52: 905-25.

7.- Ohnishi H, Inomata H, Watanabe T, et al: Clinical utility of thyroid ultrasonography in the diagnosis of congenital hypothyroidism. Endocr J 2002; 49: 293-7.

8.- Takashima S, Nomura N, Tanaka H, Itoh Y, Miki K, Harada T: Congenital hypothyroidism: Asessment with ultrasound. Am J Neuroradiol 1995; 16: 1117-23.

9.- Gruters A, Krude H: Detection and treatment of congenital hypothyroidism. Nat Rev Endocrinol 2011; 8 (2): 104-13.

10.- LaFranchi S: Approach to the Diagnosis and Treatment 
of Neonatal Hypothyroidism. J Clin Endocrinol Metab 2011; 96 (10): 2959-67.

11.- Chang YW, Lee DH, Hong YH, Hong HS, Choi DL, Seo DY: Congenital hypothyroidism: Analysis of discordant US and Scintigraphic findings. Radiology 2011; 258: 3 872-9.

12.- Ohnishi F, Sato H, Noda H, Inomata H, Sasaki N: Color Doppler-Ultrasonography: Diagnosis of ectopic thyroid gland in patients with congenital hypothyroidism caused by thyroid dysgenesis. J Clin Endocrinol Metab 2003; 88: 5145-9.

13.- Farriaux JP, Dhondt JL: Thyroid scanning ultrasound, and serum thyroglobulin in determining the origin of congenital hypothyroidism. Amer J Dis Child 1988; 142: 214-6.

14.- Ueda D, Yoto Y, Sato T: Ultrasonic assessment of the lingual thyroid gland in children. Pediatr Radiol 1998; 28: 126 .

15.- Perry RJ, Maroo S, Maclennan AC, Jones JH, Donaldson $M D C$ : Combined ultrasound and isotope scanning is more informative in the diagnosis of congenital hypothyroidism tan single scanning. Arch Diseases Child
2006; 91: 972-6.

16.- Perry R, Hollmann A, Wood A, Donaldson M: Ultrasound of the thyroid gland in the newborn: normative data. Arch Dis Child Fetal Neonatal Ed 2002; 87: F209F211.

17.- Maiorana R, Carta A, Floriddia G, et al: Thyroid Hemiagenesis: Prevalence in Normal Children and Effect on Thyroid Function. J Clin Endocrinol Metab 88 (4): 1534-6.

18.- Dias V, Campos A, Chagas A, Silva R: Congenital Hypothyroidism: Etiology. Journal of Pediatric Endocrinology \& Metabolism 2010; 23: 815-26.

19.- Sfakianakis G, Ezuddin S, Sánchez J, Eidson M, Cleveland $W$ : Pertechnetate Scintigraphy in Primary Congenital Hypothyroidism. J Nucl Med 1999; 40: 799-804.

20.- Van Vliet $G$ : Development of the thyroid gland: lessons from congenitally hypothyroid mice and men. Clin Genet 2003: 63: 445-55.

21.- Supakul N, Delaney L, Siddiqui A, Jennings S, Eugster E, Karmazyn B: Ultrasound for Primary Imaging of Congenital Hypothyroidism. AJR 2012; 199: W360W366. 